\title{
Linking genes with exercise: where is the cut-off?
}

\author{
Martin Flueck • David Vaughan · Håkan Westerblad
}

Accepted: 16 September 2010/Published online: 13 October 2010

(C) Springer-Verlag 2010

\begin{abstract}
Studies on gene-phenotype associations are a popular theme in exercise physiology. This editorial follows up on the current limitations in this quest with regard to the identification of mechanistically important relationships.
\end{abstract}

Keywords Exercise - Human - Function - Muscle · Pathway $\cdot$ Gene $\cdot$ Polymorphism $\cdot$ Redundancy

Following the introduction of and improvement in genomic technologies, there is a rapidly increasing interest in possible genetic factors that may explain differences in physical exercise performance (Bray et al. 2009). During the evaluation of manuscript submissions to the European Journal of Applied Physiology (EJAP), it has become evident that a sizeable proportion of submissions on the topic of human performance now focuses on the influence of genes (Fig. 1). This is illustrated by a series of recent papers (Zago et al. 2010; He et al. 2010; Kostek et al. 2010), including the work of Gabriel Rodríguez-Romo

Communicated by Susan Ward.

M. Flueck $(\bowtie) \cdot$ D. Vaughan

Institute for Biomedical Research into Human Movement

and Health, Manchester Metropolitan University,

Manchester M1 5GD, UK

e-mail: m.flueck@mmu.ac.uk

H. Westerblad

Department of Physiology and Pharmacology,

Karolinska Institutet, Stockholm, Sweden and colleagues published in this issue (Rodríguez-Romo et al. 2010). The results of this latter study show that neither of single polymorphisms in two candidates of muscle phenotypic control, angiotensin converting enzyme (ACE) and $\alpha$-actinin-3 (ACTN3), is associated with explosive muscle performance in young healthy adults. Given the thousands of possible gene polymorphisms and the rapidly increasing number of studies in this field, there would seem to be a perceived need for guidance to authors who are considering such submissions to EJAP.

An historical perspective appears important to bear in mind when considering the physiological significance of studies designed to map the role of genetic factors in exercise performance. The genetical approach is rooted in quantitative genetics which links gene markers with quantitative traits (Plomin et al. 2009). The usage of such methodology to resolve the mechanisms that regulate the exercise phenotype relates back to the classical work of Petit and Klissouras in twins (Klissouras et al. 1973). Their investigation laid out the discrete contribution of heritable elements which manifest in aerobic capacity. However, early studies on twins showed that environmental factors may be more important than genetic influences in dictating physical performance (Howald et al. 1976). It is now evident that both genetical and environmental cues influence the expression of an endurance/strength exercise phenotype, to a similar degree (Dempfle et al. 2008). Nevertheless, with the sophistication of molecular biological technology (for the sensitive detection of gene polymorphisms via polymerase chain reaction techniques), the genetical approach has gained further popularity (Ahmetov and Rogozkin 2009). It is then hoped that this resulting knowledge can serve, for example, to tailor exercise treatments to at risk 


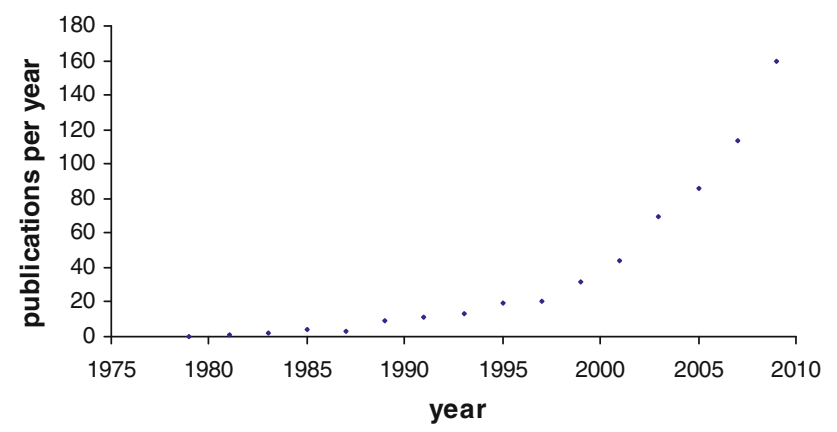

Fig. 1 Progressive rise in research interest. Scatter plot showing the numbers of publications per year on a pubmed search (http://www. ncbi.nlm.nih.gov/pubmed) with the mesh terms: "gene, performance, muscle"

populations and also to further mechanistic understanding of the biological pathways that underlie physical performance (Plomin et al. 2009).

There is however an increasing list of examples for which the effects of gene polymorphisms on selected physiological endpoints of performance are either small or lacking. These contrast with the effects that arise from full loss or gain in function mutation, which are described for certain pathologies or transgenic animals (MacArthur et al. 2008). The small effect, coupled with the controversy surrounding the functional consequences of gene polymorphisms, has shed doubts on the relevance of the genetic underpinning of athletic performance. The literature suggests that this disparity on the functional outcome of single gene polymorphisms is a consequence of the multi-factorial nature of biological pathways. With this in mind, success in probing whether a single polymorphism has an important effect on a complex trait is limited to factors with a central role in biological regulation. In most cases, the single-gene approach is likely to reduce the effect size for two reasons. Firstly, the studied factor may not be at the "bottleneck" of regulation. Secondly, the affected event may contribute only marginally to the physiological function at the whole-body level. The first factor is explained by the fact that overlapping signalling pathways are a hallmark for the robustness of biological regulation (Colobran et al. 2007). The second factor is explained, for instance, by many different tissues sharing the control over aerobic performance (Darveau et al. 2002).

Gene polymorphisms, which affect only one regulatory (tissue) component, can be important at the local level. However, the effect may be lost when assessed at the system level. This is highlighted, for instance, by the oftendebated question as to whether the heart or skeletal muscle dictates trainability of maximum oxygen uptake $\left(\dot{V} \mathrm{O}_{2} \max \right)$ (Hoppeler and Lindstedt 2006): the answer appears to be that both contribute to differing degrees (Darveau et al. 2002). Thus, the physiologically assessed endpoint may be too remote to detect the effect of a genetic modification.

The detection of the effect of a single polymorphism on a phenotype is sometimes also complicated by population differences. This can be illustrated by studies of Ins/Del (I/D) polymorphism of the ACE gene. Early studies showed an association between the ACE D allele and better performance in strength-oriented power exercise compared to endurance exercise (see refs in Rodríguez-Romo et al. 2010). However, subsequent studies have revealed a more complex picture (Table 1). Thus, there are differences between different ethnic groups, between trained and untrained subjects etc.

It follows from the above considerations that the implication of a molecular mechanism in the regulation of a phenotypic trait may not be exposed through measuring the relationship between a single point at the bottom ('the gene') and the top of a physiological pathway (e.g. function as assessed by $\dot{V} \mathrm{O}_{2}$ max or sprint performance). Thus, we suggest that future studies using a genomic paradigm to expose molecular regulation should employ a more mechanistic approach and focus on functions that are more directly related to the molecular alteration under investigation. This call for a careful test of functional relevance for gene-phenotype associations is in line with suggestions voiced regarding the molecular mechanism of metabolic disease (Loos 2009). We suggest that future studies of whether or how a single gene polymorphism may affect $\dot{V} \mathrm{O}_{2}$ max or sprint performance in different populations will most likely not advance our understanding of the underlying mechanisms that determine performance during physical exercise. 


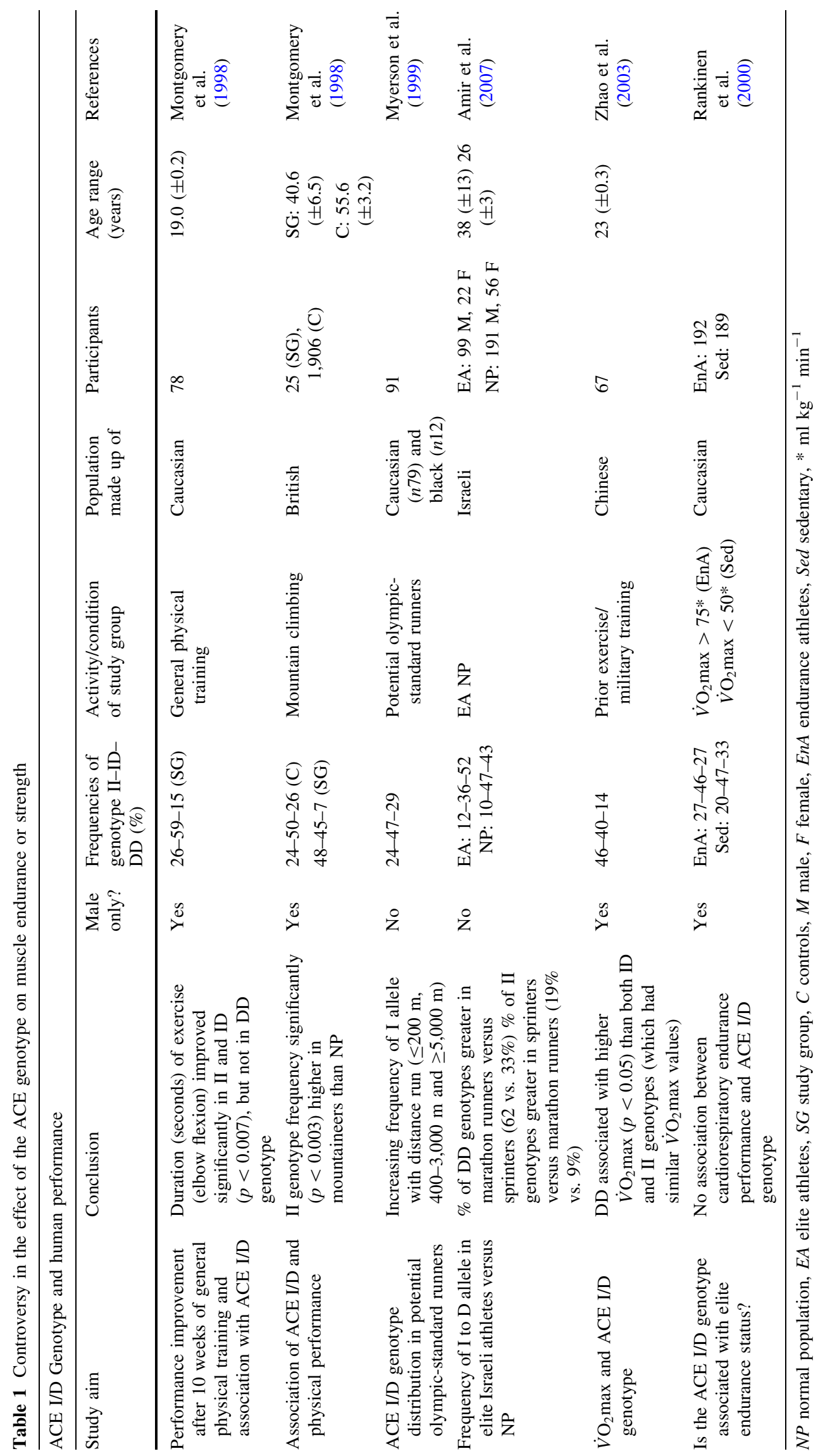




\section{References}

Ahmetov II, Rogozkin VA (2009) Genes, athlete status and trainingan overview. Med Sport Sci 54:43-71

Amir O, Amir R, Yamin C, Attias E, Eynon N, Sagiv M, Sagiv M, Meckel Y (2007) The ACE deletion allele is associated with Israeli elite endurance athletes. Exp Physiol 92:881-886

Bray MS, Hagberg JM, Perusse L, Rankinen T, Roth SM, Wolfarth B, Bouchard C (2009) The human gene map for performance and health-related fitness phenotypes: the 2006-2007 update. Med Sci Sports Exerc 41:35-73

Colobran R, Pujol-Borrell R, Armengol MP, Juan M (2007) The chemokine network I. How the genomic organization of chemokines contains clues for deciphering their functional complexity. Clin Exp Immunol 148:208-217

Darveau CA, Suarez RK, Andrews RD, Hochachka PW (2002) Allometric cascade as a unifying principle of body mass effects on metabolism. Nature 417:166-170

Dempfle A, Scherag A, Hein R, Beckmann L, Chang-Claude J, Schafer H (2008) Gene-environment interactions for complex traits: definitions, methodological requirements and challenges. Eur J Hum Genet 16:1164-1172

He ZH, Hu Y, Li YC, Bao DP, Ruiz JR, Lucia A. (2010) Polymorphisms in the calcineurin genes are associated with the training responsiveness of cardiac phenotypes in Chinese young adults. Eur J Appl Physiol Jul 1 [Epub ahead of print]

Hoppeler H, Lindstedt SL (2006) In health and in a normoxic environment, $\mathrm{VO} 2 \mathrm{max}$ is/is not limited primarily by cardiac output and locomotor muscle blood flow. J Appl Physiol 100:1415-1416

Howald H (1976) Ultrastructure and biochemical function of skeletal muscle in twins. Ann Hum Biol 3:455-462

Klissouras V, Pirnay F, Petit JM (1973) Adaptation to maximal effort: genetics and age. J Appl Physiol 35:288-293

Kostek MC, Devaney JM, Gordish-Dressman H, Harris TB, Thompson PD, Clarkson PM, Angelopoulos TJ, Gordon PM, Moyna NM, Pescatello LS, Visich PS, Zoeller RF, Seip RL, Garcia M, Li R, Zmuda JM, Delmonico MJ, Kanaya A, Hoffman EP (2010) A polymorphism near IGF1 is associated with body composition and muscle function in women from the health, aging, and body composition study. Eur J Appl Physiol May 19 [Epub ahead of print]

Loos RJ (2009) Recent progress in the genetics of common obesity. Br J Clin Pharmacol 68(6):811-829

MacArthur DG, Seto JT, Chan S, Quinlan KGR, Raftery JM, Turner N, Nicholson MD, Kee AJ, Hardeman EC, Gunning PW, Cooney GJ, Head SI, Yang N, North KN (2008) An ACTN3 knockout mouse provides mechanistic insights into the association between $\alpha$-actinin-3 deficiency and human athletic performance. Hum Mol Genet 17:1076-1086

Montgomery HE, Marshall R, Hemingway H, Myerson S, Clarkson P, Dollery C, Hayward M, Holliman DE, Jubb M, World M, Thomas EL, Brynes AE, Saeed N, Barnard M, Bell JD, Prasad K, Rayson M, Talmud PJ, Humphries SE (1998) Human gene for physical performance. Nature 393:221-222

Myerson S, Hemingway $\mathrm{H}$, Budget $\mathrm{R}$, Martin J, Humphries S, Montgomery H (1999) Human angiotensin I-converting enzyme gene and endurance performance. J Appl Physiol 87(4):13131316

Plomin R, Haworth CM, Davis OS (2009) Common disorders are quantitative traits. Nature rev 10:872-878

Rankinen T, Wolfarth B, Simoneau JA, Maier-Lenz D, Rauramaa R, Rivera MA, Boulay MR, Chagnon YC, Perusse L, Keul J, Bouchard C (2000) No association between the angiotensinconverting enzyme ID polymorphism and elite endurance athlete status. J Appl Physiol 88:1571-1575

Rodríguez-Romo G, Ruiz JR, Saniago C, Fiuza-Luces C, GonzalezFreire M, Gomez-Gallego F, Moran M and Lucia A (2010) Does the ACE I/D polymorphism, alone or in combination with the ACTN3 R577X polymorphism, influence muscle power phenotypes in young, non-athletic adults? Eur J Appl Physiol (in press)

Zago AS, Reis Silveira L, Kokubun E (2010) Effects of aerobic exercise on the blood pressure, oxidative stress and eNOS gene polymorphism in pre-hypertensive older people. Europ J Appl Physiol Jul 8 [Epub ahead of print]

Zhao B, Moochhala SM, Tham S, Lu J, Chia M, Byrne C, Hu Q, Lee LK (2003) Relationship between angiotensin-converting enzyme ID polymorphism and $\mathrm{VO}(2 \max )$ of Chinese males. Life Sci 73:2625-2630 